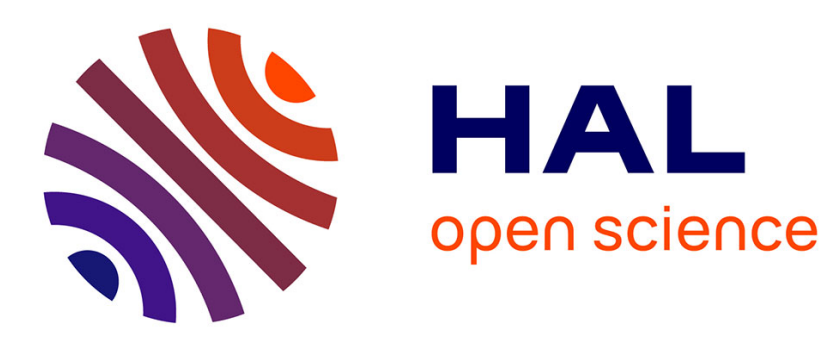

\title{
Magnetic Gold Confined in Ordered Mesoporous Titania Thin Films: A Noble Approach for Magnetic Devices
}

\author{
Leticia P. Granja, Eduardo D. Martínez, Horacio Troiani, Clément Sanchez,
} Galo J. A. A. Soler Illia

\section{- To cite this version:}

Leticia P. Granja, Eduardo D. Martínez, Horacio Troiani, Clément Sanchez, Galo J. A. A. Soler Illia. Magnetic Gold Confined in Ordered Mesoporous Titania Thin Films: A Noble Approach for Magnetic Devices. ACS Applied Materials \& Interfaces, 2017, 9 (1), pp.965 - 971. 10.1021/acsami.6b15189 . hal-01445065

\section{HAL Id: hal-01445065 \\ https://hal.sorbonne-universite.fr/hal-01445065}

Submitted on 24 Jan 2017

HAL is a multi-disciplinary open access archive for the deposit and dissemination of scientific research documents, whether they are published or not. The documents may come from teaching and research institutions in France or abroad, or from public or private research centers.
L'archive ouverte pluridisciplinaire HAL, est destinée au dépôt et à la diffusion de documents scientifiques de niveau recherche, publiés ou non, émanant des établissements d'enseignement et de recherche français ou étrangers, des laboratoires publics ou privés. 


\title{
Magnetic Gold Confined in Ordered Mesoporous Titania
} Thin Films: a Noble Approach for Magnetic devices

\author{
Leticia P. Granja, ${ }^{a}$ Eduardo D. Martínez, ${ }^{b, \dagger}$ Horacio Troiani, ${ }^{c}$ Clément Sanchez, ${ }^{d}$ Galo
} J. A. A. Soler Illia ${ }^{e, *}$

a Departamento de Física de la Materia Condensada, Gerencia de Investigación y Aplicaciones, Centro Atómico Constituyentes, Comisión Nacional de Energía Atómica, Av. Gral. Paz 1499, B1650KNA, San Martín, Buenos Aires, Argentina.

b Gerencia Química, Centro Atómico Constituyentes, Comisión Nacional de Energía Atómica, Av. Gral. Paz 1499, B1650KNA, San Martín, Buenos Aires, Argentina.

c División Bajas Temperaturas, Gerencia Física, Instituto de Nanociencia y Nanotecnología (INN),Centro Atómico Bariloche, Comisión Nacional de Energía Atómica, Av. Bustillo 9500 (8400), S. C. de Bariloche, Río Negro, Argentina.

d UPMC Univ. Paris 06, CNRS, Collège de France, UMR 7574, Laboratoire Chimie de la Matière Condensée de Paris, Collège de France, 11 place Marcelin Berthelot, 75005, Paris, France).

e Instituto de Nanosistemas, Universidad Nacional de General San Martín, Av. 25 de Mayo y Francia, 1650, San Martín, Buenos Aires, Argentina.

†Present address: Instituto de Física Gleb Wataghin, Universidad Estadual de Campinas (UNICAMP), R. Sérgio Buarque de Holanda, 777, Cidade Universitária, Campinas, SP, 13083859, Brasil.

\begin{abstract}
In the last decade, the surprising magnetic behavior of gold nanoparticles has been reported. This unexpected property is mainly attributed both to size and surface effects. Mesoporous thin films are ideal matrices for metallic nanoparticles inclusion due to their highly accessible and tailorable pore systems that lead to completely tunable chemical environments. Exploiting these features, we synthesized Au nanoparticles within mesoporous titania thin films (film thickness $\sim 150 \mathrm{~nm}$ and pore diameter $\sim 5 \mathrm{~nm}$ ), and we studied their magnetic properties under confinement. We present here the results of the magnetization as a function of temperature and magnetic field for this system,
\end{abstract}


which are consistent with the previously reported for free (unconfined) thiol-capped gold nanoparticles. The successful inclusion of stable magnetic Au nanoparticles within transparent mesoporous thin films opens the gates for the application of these nanocomposites in 2D microdevices technology and magneto-optical devices. 


\section{INTRODUCTION}

Gold nanoparticles (GNPs) have been intensively studied due to their wide possibilities of applications in optics, catalysis and sensing, among other fields. In the last decade, it was surprisingly found that GNPs could also present magnetic properties, which has opened a thriving research area. ${ }^{1}$ These unusual magnetic properties have been ascribed to the nanoparticles size or surface functionalization, and many different GNPs systems have been studied by magnetometry techniques. ${ }^{2,3,4}$ Although the details are still to be clarified, the chemically induced magnetism is considered the main responsible for the magnetic moment in GNPs or clusters. The emergence of the magnetic properties has been studied by varying the stabilizing ligand. ${ }^{5,6}$ It is nowadays well established that in general noble metal nanoclusters and nanoparticles can form high spin states, and a size dependence of the magnetic properties has been observed in surface-capped nanoparticles or clusters based on non-magnetic metals (i.e. Au, $\mathrm{Ag}, \mathrm{Cu}, \mathrm{Pd}$ or Pt). ${ }^{7,8,9}$

Although some works have proposed alternative mechanisms, such as self-sustained persistent currents of conduction electrons, at this moment there is general consensus about the orbital nature of this magnetic moment, ${ }^{1,10}$ The appearance of magnetization in capped GNPs was proposed to be associated with a spin symmetry breaking related with the $5 \mathrm{~d}$ and $6 \mathrm{~s}$ electrons of the Au atoms involved in the chemical bond with the ligands. The presence of the capping agents at the surface changes the number of uncompensated spins, which in turn modifies the relative spin densities at the Fermi energy, thus creating a non-zero magnetic moment. ${ }^{6}$ Maitra et $a l^{9}{ }^{9}$ evidenced experimentally that the saturation magnetization increases with capping and depends on the strength of the metal-sulfur bond. Although the origin of GNPs magnetism has not been fully elucidated yet, and there is a lack of reproducibility of the magnetic behavior between reports, nowadays the magnetism of gold at the nanoscale is accepted. ${ }^{1,11}$

At present, the role of the surface and the interface of noble metal thin layers are being particularly considered in magnetic devices research. As an example, magnetic proximity effects have been reported at the $\mathrm{Pt} / \mathrm{Y}_{3} \mathrm{Fe}_{5} \mathrm{O}_{12}$ interfaces in magnetoresistance devices. ${ }^{12,13}$ Moreover, it was recently found that magnetization is induced in the $\mathrm{Au}$ thin layer of superconducting spin valves. ${ }^{14}$ In the light of these findings, magnetic structures based in noble metal nanoparticles is becoming a growing field, and might inspire the design of novel magnetic, opto-magnetic and spintronic devices. 
Materials with highly controlled pore size are very interesting matrices for the immobilization of magnetic metallic nanospecies. Platinum clusters have been immobilized in zeolites, which affect the hydrogen adsorption properties, leading to controlling the catalytic and magnetic behaviors. ${ }^{15}$ Very recently, the magnetism of GNPs within hollow mesoporous silica particles has been exploited in multifunctional nanoparticles for theranostics. ${ }^{16}$ In order to fully exploit their potential in $2 \mathrm{D}$ magnetic devices such as magnetic sensors and memory devices, GNPs need to be efficiently incorporated into thin films, permitting an easy positioning and handling of the magnetic species, which is still a challenge. ${ }^{17}$ Ordered mesoporous thin films ${ }^{18}$ arise as a promising matrix to solve this limitation, by using them as robust frameworks to be filled with the nanoparticles desired, which results in enhanced nanoparticle stability and high accessibility for analytes. ${ }^{19,20}$ In addition, simple and affordable patterning methods that rely on chemical or lithographic routes can be applied to these composites in order to specifically locate the nanoparticles in the micron or submicron scale. ${ }^{21,22}$

In this work, we present an efficient and robust method to incorporate magnetic $\mathrm{Au}$ nanoparticles within the pore system of highly ordered mesoporous titania thin films ${ }^{23}$ combining a soft reduction method and thiol capping. Controlled reduction and capping process were essential towards obtaining stable magnetic GNPs confined inside the mesopores. The method is highly reproducible and leads to protected GNPs, whose magnetic properties are constant throughout the samples and conserved along time. These nanocomposites permit to create magnetically functionalized mesoporous thin films, and open the gate for exploiting GNPs properties in thin film related applications such as opto-magnetic ${ }^{24}$ and spintronic devices.

\section{EXPERIMENTAL}

\section{Synthesis of mesoporous titania thin films}

Mesoporous $\mathrm{TiO}_{2}$ thin films (MTTF) were synthesized by dip-coating, using a titania sol in the presence of a supramolecular polymer template. ${ }^{23}$ A stock solution of $\mathrm{TiCl}_{4}$ in ethanol was prepared by adding $19 \mathrm{~g}$ of $\mathrm{TiCl}_{4}$ in $181 \mathrm{~g}$ of absolute ethanol in a cold bath. To $20 \mathrm{~g}$ of this solution, it was added $0.56 \mathrm{~g}$ of Brij58 as supramolecular template and $1.8 \mathrm{~g}$ of water to promote the hydrolysis of the Ti precursor. The molar ratio between components $\mathrm{TiCl}_{4}: \mathrm{Brij} 58: \mathrm{H}_{2} \mathrm{O}: \mathrm{EtOH}$ was 1:0.05:10:40. 
The prepared sol was heated up to $32{ }^{\circ} \mathrm{C}$ and dip coated at a withdrawal speed of 3.0 $\mathrm{mm} \cdot \mathrm{s}^{-1}$ in a controlled environment of $35 \%$ relative humidity $(\mathrm{RH})$. Double side polished silicon wafers (University Wafers, USA) were used as substrates, therefore mesoporous films were deposited simultaneously over the two sides of the substrates. After deposition, the films were kept for 24 hours in a chamber at $50 \% \mathrm{RH}$ to promote stabilization of the mesostructure, and then submitted to $60{ }^{\circ} \mathrm{C}$ for 30 minutes, $130{ }^{\circ} \mathrm{C}$ for additional 30 minutes and finally calcined at $350{ }^{\circ} \mathrm{C}$ for $2 \mathrm{~h}^{25}$ Films were then washed with acetone and immersed for two hours in an ethanol:water 1:1 v:v mixture under strong agitation in order to remove any residue from the pyrolysis of the surfactant. Films were finally dried at $130{ }^{\circ} \mathrm{C}$. Mesoporous $\mathrm{TiO}_{2}$ films templated with Brij 58 will be referred hereafter as TB.

\section{Loading mesoporous films with Au nanoparticles}

Mesoporous $\mathrm{TiO}_{2}$ films were loaded with $\mathrm{Au}$ by controlling the nucleation and growth of GNPs in cycles of adsorption and reduction of $\mathrm{AuCl}_{4}{ }^{-}$. The procedure, described and analyzed in detail in previous work, ${ }^{26}$ was performed by immersing the films in a $1 \mathrm{mM}$ aqueous solution of $\mathrm{HAuCl}_{4} \cdot 3 \mathrm{H}_{2} \mathrm{O}$ at $\mathrm{pH} 4$, controlled by addition of $\mathrm{NaOH}$. After 1 minute, films were extracted, washed with deionized water, and immersed in $\mathrm{NaBH}_{4} 10$ $\mathrm{mM}$ aqueous solution for another minute. This reduction step cycle (RS) was repeated 16 times in total. An intermediate step was added after each two reduction steps to favor the adsorption of a thiol molecule by immersing the films in an ethanol solution of octanethiol (OT, Sigma-Aldrich, 98.5\%) $10 \mu \mathrm{M}$ for 30 minutes. The objective of this procedure was to limit the growth of the GNPs by thiol capping, and favor the development of new nucleation sites instead. Particular care was set in avoiding contact of the precursor solutions and samples with iron or any other magnetically active substances during the synthesis and measurement procedures, in order to discard the presence of magnetic impurities.

\section{Thin Film Characterization}

Mesoporous thin films thickness, optical constants and porosity were characterized by spectroscopic ellipsometry in a commercial SOPRA GES5 multispectral ellipsometer in microspot configuration; the data was analyzed by the use of Winelli II software. Ellipso-porosimetry was performed in order to determine film pore volume and pore diameter, by means of controlled condensation of water vapor inside porosity and 
measure of the subsequent change in refractive index of the film, following Boissière et $\mathrm{al.}^{27}$

Field emission-scanning electron microscopy (FE-SEM) images were obtained with a ZEISS LEO 982 GEMINI field emission electron microscope using an in-lens detector to improve resolution. Energy Dispersive Spectroscopy (EDS) was performed at the FE$\mathrm{SEM}$, to quantify the amount of $\mathrm{Au}$ in the samples by resolving the atomic ratio $\mathrm{Au}: \mathrm{Ti}(r)$. High resolution transmission electron microscopy (HR-TEM) was performed in a Philips CM 200 electron microscope operating at $200 \mathrm{kV}$ equipped with a $\mathrm{LaB}_{6}$ emission filament and an ultra-thin objective lens for high resolution images. Samples for HR-TEM measurements were prepared by depositing a small amount of pieces scratched off the films onto an ethanol drop placed on carbon coated copper grids.

Magnetization of the GNP@MTTF sample was measured in a MPMS Quantum Design SQUID magnetometer. It was studied as a function of temperature (T) and applied magnetic field $(\mathrm{H})$ in the ranges of $5-300 \mathrm{~K}$ and up to $5 \mathrm{~T}$ respectively.

\section{RESULTS}

Spectroscopic ellipsometry was used to determine the thickness and refractive index at $633 \mathrm{~nm}$ and $0 \%$ relative humidity $(\mathrm{RH})$ of the TB films, finding values of $147 \pm 6 \mathrm{~nm}$ and $1.701 \pm 0.004$ respectively. By controlling the RH in a closed chamber around the sample, ellipsometry could be used to obtain a water adsorption isotherm from which the porosity and the pore size distribution (PSD) could be extracted. The results presented in Fig. 1 show a type IV isotherm with an $\mathrm{H} 2$ hysteresis loop, characteristic of a mesoporous structure formed by pores with restrictions. The porous volume fraction obtained of $32 \%$ is formed by pores of $4.9 \pm 0.9 \mathrm{~nm}$ in diameter, connected by open necks of $3.2 \pm 0.4 \mathrm{~nm}$ wide. Spectroscopic ellipsometry ${ }^{28}$ was also exploited to study the optical properties of GNP@MTTF at 0\% RH. It was found that the plasmonic features of GNPs are retained together with the magnetic properties. This subject is discussed in-depth at the SI.

Electronic microscopy was used to analyze the framework of MTTF and the GNP@MTTF samples (see Fig. 2). The characteristic long range highly ordered mesoporous structure obtained for TB films ${ }^{23}$ is displayed by TEM (Fig. 2-A) and small 
angle X-Ray scattering (SAXS) at $3^{\circ}$ grazing incidence (inset of Fig. 2-A). The GNP@MTTF nanocomposite displays a homogeneous dispersion of 4-6 nm spherical GNPs located evenly across and along the film thickness (Fig. 2-B to 2-F, calculated from TEM images, average of 200 nanoparticles).

Considering the film porosity, the density of the $\mathrm{TiO}_{2}$ matrix and the atomic ratio $\operatorname{Au}: \operatorname{Ti}(r)$ obtained by EDS, an estimated value of the gold filling fraction $(F)$ can be calculated using Eq. $1{ }^{26}$ where $V p$ is the accessible porous fraction $(V p=0.32$ from Fig. 1), $\delta_{A u}$ and $M_{A u}$ are respectively the bulk density and the molecular weight of gold (19.3 $\left.\mathrm{g} \mathrm{cm}^{-3}, 196.96 \mathrm{~g} \mathrm{~mol}^{-1}\right), \delta_{\mathrm{TiO} 2}$ is the bulk density of anatase $\mathrm{TiO}_{2}\left(3.8985 \mathrm{~g} \mathrm{~cm}^{-3}\right)$, which is the main crystallographic phase present in the films, Error! Bookmark not defined. and $M_{\text {TiO2 }}$ is the molecular weight $\left(79.89 \mathrm{~g} \mathrm{~mol}^{-1}\right)$. The filling fraction $F$ represents the volume fraction of the porosity $(V p)$ of the film occupied by GNPs, from which the total film volume occupied by GNPs (volume filling fraction, VFF) is calculated. The number of $\mathrm{Au}$ atoms in each square millimeter of film, $147 \mathrm{~nm}$ thick, was also calculated. The resulting values of the EDS analysis, $F$ and VFF are summarized in Table 1.

$$
F(\%)=\frac{r \delta_{T i O 2} M_{A u}\left(1-V_{p}\right)}{\delta_{A u} M_{T i O 2} V_{p}} \times 100
$$

Eq. 1

\begin{tabular}{cccc}
\hline \hline $\boldsymbol{F ~ ( \% )}$ & VFF (\%) & Atomic ratio Au:Ti & Au atoms $/ \mathbf{m m}^{2}$ \\
\hline 22.6 & 7.3 & 0.27 & $6.3 \times 10^{14}$
\end{tabular}

Table 1 Composition of MTTF after gold infiltration and thiol capping analyzed by ellipsometry and EDS.

The magnetization $(\mathrm{m})$ as a function of the applied magnetic field $(\mathrm{H})$ was measured at different temperatures for the GNP@MTTF sample. The magnetization measurements of film samples are always made up by the sum of the film and the substrate contributions. In our case, we aimed to elucidate the relevant features of the magnetic results inherent to the GNPs, which are confined within the TB film deposited on both sides of a double side polished (DSP) silicon substrate. The crude data information 
obtained from the magnetometer is shown, for $300 \mathrm{~K}$ and $5 \mathrm{~K}$, at the inset of Fig. 3-B. The magnetic response is governed by a linear negative-slope which is independent of temperature, due to the diamagnetic contribution of the $\mathrm{TiO}_{2}$ film, the $\mathrm{Si}$ substrate and the sample mounting. Fig. 3-A and 3-B display the magnetization results once the diamagnetic slope was subtracted. Note that the resolution range used to measure in the magnetometer is conditioned by the whole magnetic signal (Inset of Fig. 3-B), which is about ten times higher than the non-linear features extracted from them (Fig. 3-A and 3B). Therefore these measurements of the magnetization of GNPs included inside the thin film oxide matrix are more indirect, and consequently more noisy and weaker, than the measurements of the GNPs alone, which are already widely reported.

Within this framework, it was confirmed that the magnetization results displayed here are reproducible from sample to sample and the magnetic properties of the samples were preserved along the several months that the experiments lasted. In Fig 3-A and 3-B are compared two session measurements for $300 \mathrm{~K}$ and $5 \mathrm{~K}$ respectively, where it can be appreciated clear differences with temperature. These are important results considering sample-to-sample reproducibility and the stabilization of the GNPs embedded in the porous matrix, which is a well documented feature in metal nanoparticle-mesoporous oxide nanocomposite systems. ${ }^{20}$

The magnetic behavior of the TB films without GNPs was also studied. It was found that the magnetization is mostly independent of temperature and that there are no clear differences between the zero field cooling (ZFC) and field cooling (FC) curves (Figure 4). Slight deviations from the diamagnetic behavior at low temperatures are consistent with the electronic characteristics previously reported for $\mathrm{TiO}_{2}{ }^{29,30}$ and doped silicon.31,32 Following the same analysis performed with the GNP@MTTF results, the negative linear contribution was deducted from the $\mathrm{m}(\mathrm{H})$ curves (inset A of Fig. 4) of the TB film. Comparing with the obtained for GNP@MTTF, which saturates at $8 \times 10^{-4}$ $\mathrm{emu} / \mathrm{g}$ at $300 \mathrm{~K}$ (normalized by the sample mass), the non-linear component of the $\mathrm{m}(\mathrm{H})$ of the TB film (see Inset B of Fig. 4) is independent of T and does not exceed $4.88 \times 10^{-4}$ $\mathrm{emu} / \mathrm{g}$. Therefore, it should not be interpreted as a hysteresis loop or any other reliable magnetic behavior. It is known that for small magnetic signals, the measurements are very sensitive to some measurements settings. One of the most critical is the SQUID center procedure, what introduces in many cases very confusing artifacts. ${ }^{33}$ 
With the aim of comparing our findings with those already reported for other GNPs systems, we estimated the magnetic moment (M) per $\mathrm{Au}$ atom from the $\mathrm{Au}$ content obtained by EDS (see Table 1). Figure 5-A displays $\mathrm{M}(\mathrm{H})$ results measured at different temperatures between $300 \mathrm{~K}$ and $5 \mathrm{~K}$. It can be observed that $\mathrm{M}$ increases and the hysteresis appears with the decrease of temperature. The coercive field $\left(H_{c}\right)$ reaches a value of $H_{c}=0.045 \mathrm{~T}$ at $5 \mathrm{~K}$ (see inset of Fig. 5-A), in good agreement with the values previously reported in literature. ${ }^{1,4,5}$ The saturation magnetic moment $\left(m_{S}\right)$ is $\sim 0.07 \mu_{B} /$ $A u$ atom at $5 \mathrm{~K}$. Regarding the small mass of GNPs present in the MTTF structure and the $\sim 50 \%$ uncertainty involved in the estimation, it is remarkable that the $m_{s}$ obtained is well included within the wide range, 0.002 to $0.3 \mu_{B} / A u$ atom, reported for similar thiol-capped GNPs. ${ }^{1,4,16}$

In order to understand the magnetic behavior involved in these systems, the $M(H)$ curves of Fig. 5-A were plotted together as a function of H/T in Fig. 5-B. It can be noted that the $\mathrm{M}(\mathrm{H} / \mathrm{T})$ reversible loops merge into the same curve above $100 \mathrm{~K}$ indicating the presence of a superparamagnetic state. At low temperatures, it can be appreciated in Fig. 5-B that $\mathrm{M}(\mathrm{H} / \mathrm{T})$ curves deviates from this behavior and hysteresis in $\mathrm{M}(\mathrm{H})$ appears below $50 \mathrm{~K}$, suggesting that the system would become blocked.

As a complement of the former observations, Figure 6 displays the results of the magnetization as a function of temperature, performed with $\mathrm{H}=0.1 \mathrm{~T}$, for the Zero Field Cooling (ZFC) and Field Cooling (FC) measurement modes. It can be seen that ZFC and FC curves join into the same $\mathrm{M}(\mathrm{T})$ above $150 \mathrm{~K}$, reinforcing the idea of a low temperature blocked state. Dutta et al. ${ }^{34}$ had previously reported a blocking temperature of $\sim 50 \mathrm{~K}$ in $\sim 5 \mathrm{~nm}$ dodecanethiol-caped GNPs. Looking more in detail, a peak can be appreciated at $\sim 80 \mathrm{~K}$ and $\sim 45 \mathrm{~K}$ respectively for $\mathrm{FC}$ and $\mathrm{ZFC}$ curves. This behavior has been previously observed in thiol-capped GNPs and seems to be directly associated with the magnetic mechanisms present in these systems. ${ }^{9,35}$

Furthermore, low $\mathrm{T}$ magnetic interactions are evidenced in the non-zero magnetic moment for $\mathrm{H}=0$. Regarding the GNPs size, the presence of remnant magnetization and coercive field could not be related with an inner magnetic domain structure. Thus, the interactions between nanoparticles emerge as the main candidates to explain the magnetic behavior observed at low T. ${ }^{1}$ 
Regarding the consensus about a chemically induced magnetism, favored by the interactions with OT at the Au-S bonding, ${ }^{4,6}$ the main contribution to the magnetization for each particle could be originated at the superficial Au atoms. ${ }^{9}$ In this direction, we could consider only the external monatomic Au shell of the particles, calculated for the particle size distribution (inset of Fig. 2-B). The value we obtained for $m_{s}$ in this way is $\sim 0.3 \mu \mathrm{B} /$ superficial Au atom, which is significantly higher than the one reported by Crespo et al., who estimated $0.036 \mu \mathrm{B} / \mathrm{Au}$-S bonding for dispersed thiol-capped GNPs of $1.4 \mathrm{~nm}$ size. ${ }^{5}$

It is usually assumed in the literature that the $m_{s}$ dispersion reported could be related with a non-homogenous magnetic behavior of the GNPs within a same sample. In our case, the MTTF mesostructure would confine the GNPs and limit their size. This confinement along with the procedure design for the OT capped GNPs synthesis would contribute together to obtain a more homogenous magnetic behavior for our GNP@MTTF samples. Moreover, Donnio et al. ${ }^{36}$ reported ferromagnetic-like behavior for dendrimer-coated GNPs self-assembled in a cubic array presumably related with the presence of the mesoscale order. This would suggest that also the order of the mesoporous matrix could be relevant in our case. Further experiments are in due course to shed light on this subject.

In summary, we present here for the first time the magnetic response of GNPs embedded and in-situ generated in semiconductor $\mathrm{TiO}_{2}$ mesoporous thin films. We demonstrate that the magnetic results obtained from the GNP@MTTF are consistent with previous reports for dispersed thiol-capped GNPs systems, manifesting low temperature remnant magnetization. These highly stable and reproducible magnetic nanostructures formed in ordered mesoporous thin films, are compatible with current microelectronics fabrication processes. These results also show the importance of the materials processing (in this case, the in-situ synthesis-reduction-capping cycle) in the magnetic properties of the nanocomposite system. Inclusion of stable GNPs in accessible mesoporous matrices opens the door to extending the applications of GNPs beyond the present nanoparticle domains, inspiring the design of novel magnetic and opto-magnetic thin film devices. 
1

2

3

4

5

6

7

8

9

10

11

12

13

14

15

16

17

18

19

20

21

22

23

24

25

26

27

28

29

30

31

32

33

34

35

36

37

38

39

40

41

42

43

44

45

46

47

48

49

50

51

52

53

54

55

56

57

58

59

60

\section{ACKNOWLEDGEMENTS}

This work was funded by PIP 112-200801-00038 (CONICET), PICT 2087 and 20153526 (ANPCyT) and ECOS CONICET-CNRS (A08E05). L.P.G., G.J.A.A.S.I. and H. T are CONICET staff members. We thank Solange Di Napoli and Andrea Barral for fruitful discussions. Magnetometry measurements were performed in a SQUID belonging to the National Magnetism System (MINCYT).
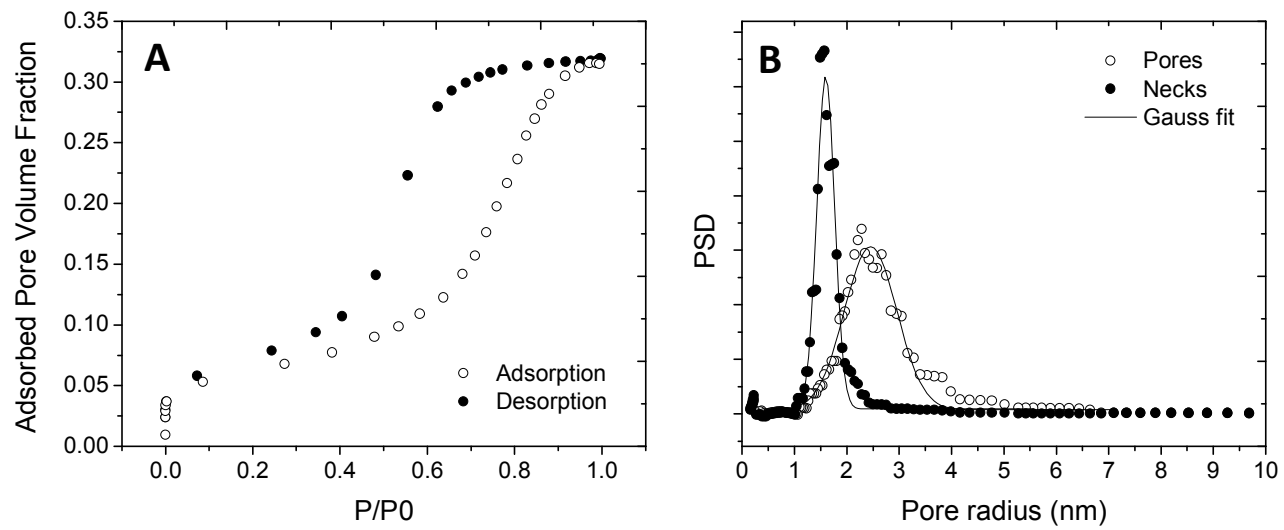

Figure 1. Water adsorption-desorption isotherm (A) and PSD (B) of mesoporous thin film TB/Si dip-coated at $3 \mathrm{~mm} \cdot \mathrm{s}^{-1}$ obtained by spectroscopic ellipsometry. 


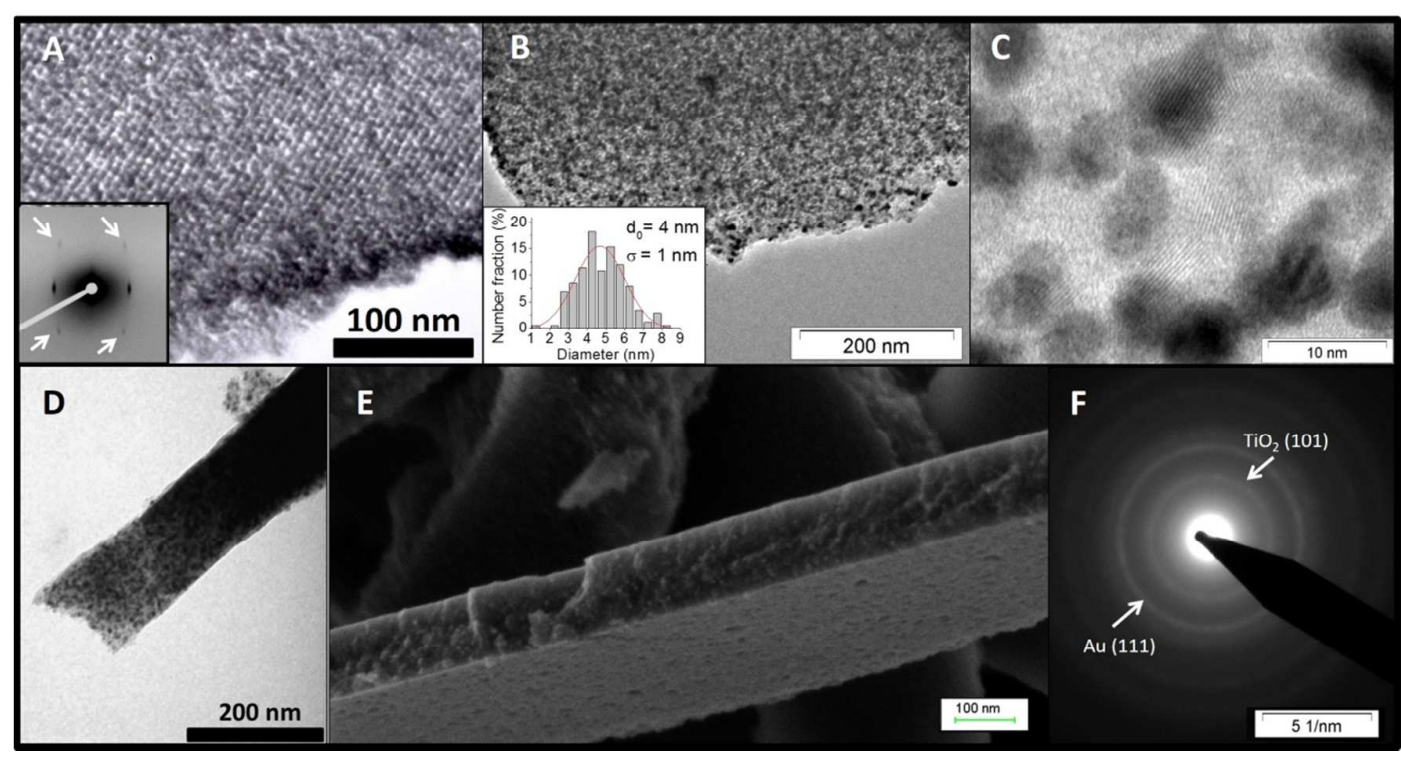

Figure 2. TEM image of a highly ordered MTTF deposited on glass (A) and small angle $\mathrm{x}$-ray scattering (SAXS) at $3^{\circ}$ grazing incidence showing the large-scale mesoporous order of these systems (inset). Large scale (B) and high magnification (C) TEM images of GNP@MTTF. Inset: particle size distribution extracted from multiple images. Cross section view of the mesoporous GNP@MTTF sample revealing the homogeneous distribution of particles across the film thickness as view by TEM (D) and FE-SEM (E). Selected Area Electron Diffraction showing the crystalline nature of the titania matrix (anatase) and GNPs (F). 


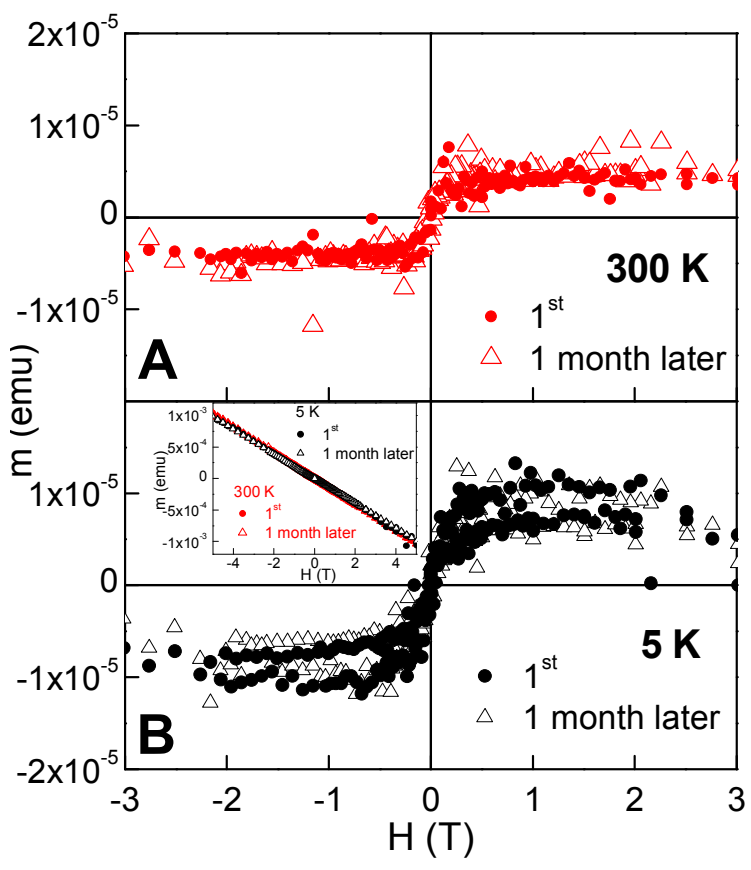

Figure 3. Magnetization (m) as a function of the applied magnetic field (H) at $300 \mathrm{~K}$ (A) and $5 \mathrm{~K}$ (B) for GNP@MTTF comparing measurements performed at different times, where the linear contribution was previously subtracted. Inset: $\mathrm{m}(\mathrm{H})$ results for $300 \mathrm{~K}$ (red) and $5 \mathrm{~K}$ (black) as obtained directly from the SQUID, without any data processing. 


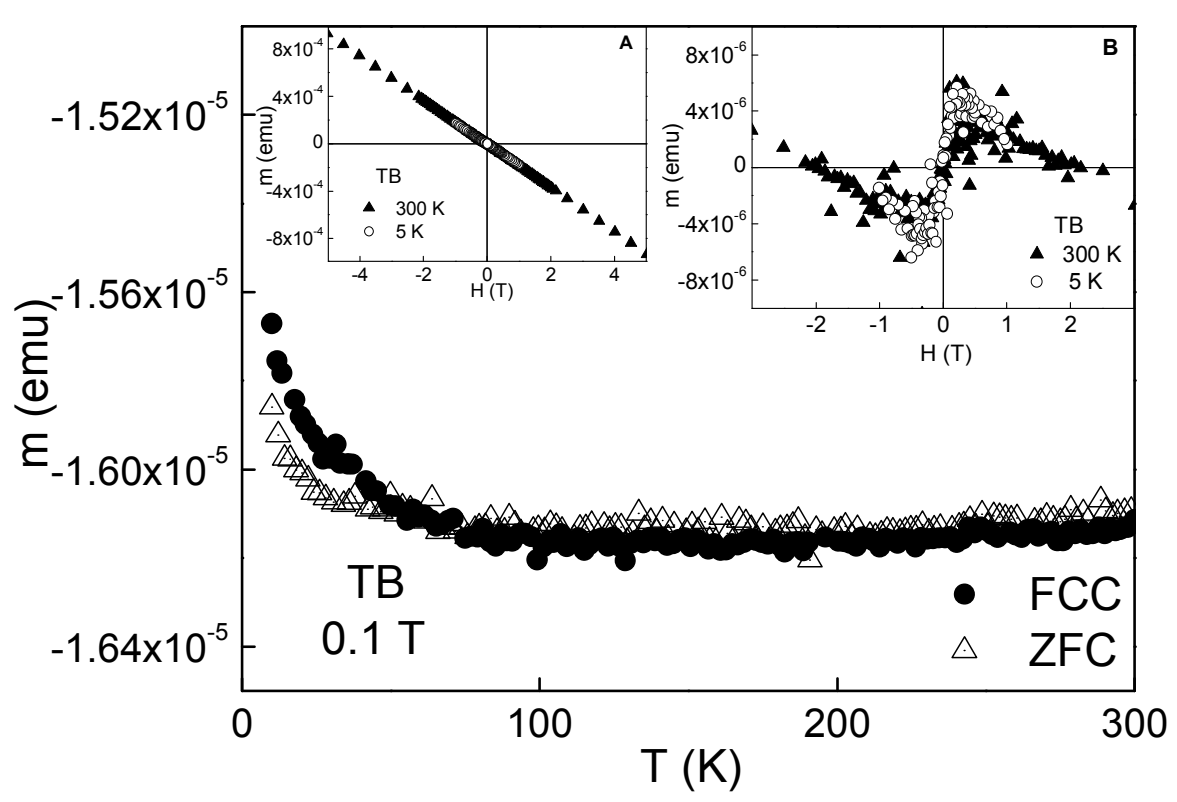

Figure 4. Magnetization (m) as a function of temperature (T) for the TB film, measured in field cooling (FC) and zero field cooling (ZFC) modes with $\mathrm{H}=0.1 \mathrm{~T}$. Inset $\mathrm{A}$ : $\mathrm{m}(\mathrm{H})$ as obtained from the SQUID for $300 \mathrm{~K}$ and $5 \mathrm{~K}$. Inset B: The same $\mathrm{m}(\mathrm{H})$ results after the subtraction of the negative slope of the diamagnetic contribution. 


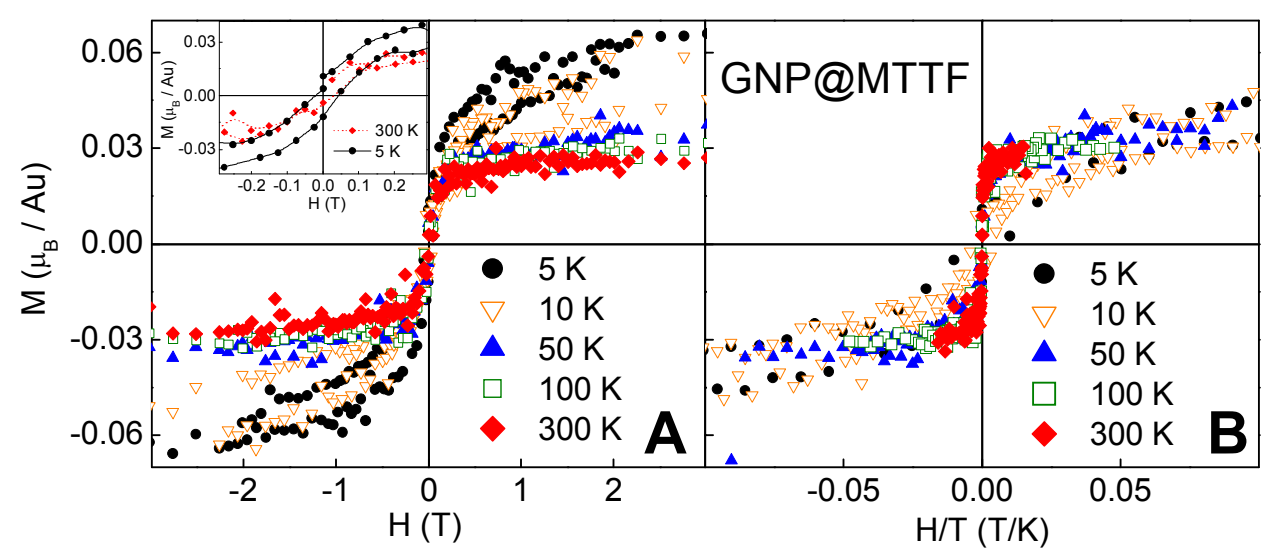

Figure 5. The magnetic moment (M) of the GNP@MTTF sample, measured as a function of the applied magnetic field $(\mathrm{H})$ at different temperatures (T) (A), and displayed as $\mathrm{M}$ versus $\mathrm{H} / \mathrm{T}$. Inset: $\mathrm{M}(\mathrm{H})$ comparing the low $\mathrm{H}$ region for $5 \mathrm{~K}$ and $300 \mathrm{~K}$ curves. 


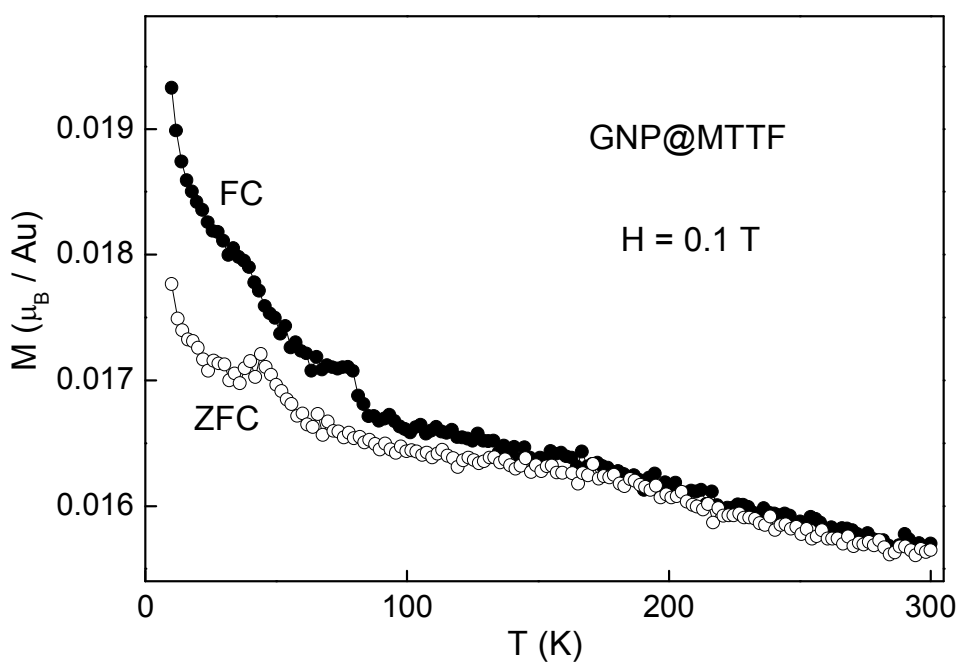

Figure 6. Zero Field Cooling (ZFC) and Field Cooling (FC) magnetic moment (M) as a function of temperature $(\mathrm{T})$, measured with an applied field $(\mathrm{H})$ of $0.1 \mathrm{~T}$, for the GNP@MTTF sample. Hollow and filled symbols correspond to ZFC and FC curves respectively. The diamagnetic contribution was already subtracted.

\section{References}

${ }^{1}$ Nealon, G. L.; Donnio, B.; Greget, R.; Kappler, J-P ; Terazzi, E.; Gallani J-L. Magnetism in Gold Nanoparticles. Nanoscale, 2012, 4, 5244-5258.

${ }^{2}$ Donnio, B.; Derory, A.; Terazzi, E.; Drillon, M.; Guillon, D.; Gallani, J-L. Very Slow HighTemperature Relaxation of the Remnant Magnetic Moment in $2 \mathrm{~nm}$ Mesomorphic Gold Nanoparticles. Soft Matter, 2010,6, 965-970.

${ }^{3}$ Lloveras, V.; Badetti, E.; Chechik, V.; Vidal-Gancedo, J. Magnetic Interactions in SpinLabeled Au Nanoparticles. J. Phys. Chem. C, 2014, 118, 21622-21629.

${ }^{4}$ Hori, H.; Yamamoto, Y.; Iwamoto, T.; Miura, T.; Teranishi, T.; Miyake. M. Diameter Dependence of Ferromagnetic Spin Moment in Au Nanocrystals. Phys. Rev. B, 2004, 69, 174411.

${ }^{5}$ Crespo, P.; Litrán, R.; Rojas, T.C.; Multigner, M.; de la Fuente, J.M.; Sánchez-López, J. C.; García, M. A.; Hernando, A.; Penadés, S.; Fernández, A. Permanent Magnetism, Magnetic Anisotropy, and Hysteresis of Thiol-Capped Gold Nanoparticles. Phys. Rev. Lett., 2004, 93 , 087204. 
${ }^{6}$ Krishna, K. S. ; Tarakeshwar, P.; Mujica, V.; Kumar, C. S. S. R. Chemically Induced Magnetism in Atomically Precise Gold Clusters. Small, 2014, 10, 907-911.

${ }^{7}$ Garitaonandia, J. S.; Insausti, M.; Goikolea, E.; Suzuki, M.; Cashion, J. D.; Kawamura, N.; Ohsawa, H.; Gil de Muro, I.; Suzuki, K.; Plazaola, F.; Rojo, T. Chemically Induced Permanent Magnetism in $\mathrm{Au}, \mathrm{Ag}$, and $\mathrm{Cu}$ Nanoparticles: Localization of the Magnetism by Element Selective Techniques. Nano Lett., 2008, 8, 661-667.

${ }^{8}$ Roduner, E.; Jensen, C. Magnetic Properties and the Superatom Character of 13-Atom Platinum Nanoclusters. Magnetochemistry, 2015, 1, 28-44.

${ }^{9}$ Maitra, U.; Das, B.; Kumar, N.; Sundaresen, A.; Rao, C.N. R. Ferromagnetism Exhibited by Nanoparticles of Noble Metals. Chem. Phys. Chem., 2011, 12, 2322-2327.

${ }^{10}$ Gréget, G.; Nealon, L.; Vileno, B.; Turek, P.; Mény, C.; Ott, F.; Derory, A.; Voirin, E.; Rivière, E.; Rogalev, A.; Wilhelm, F.; Joly, L.; Knafo, W.; Ballon, G.; Terazzi, E.; Kappler, J-P.; Donnio, B.; Gallani, J-L. Magnetic properties of gold nanoparticles: a room-temperature quantum effect. Chem. Phys. Chem., 2012, 13, 3092-3097.

${ }^{11}$ Suzuki, M.; Kawamura, N.; Miyagawa, H.; Garitaonandia, J. S.; Yamamoto, Y.; Hori, H. Measurement of a Pauli and Orbital Paramagnetic State in Bulk Gold Using X-Ray Magnetic Circular Dichroism Spectroscopy. Phys. Rev. Lett., 2012,108, 047201.

${ }^{12}$ Liang, X.; Zhu, Y.; Peng, B.; Deng, L.; Xie, J.; Lu, H.; Wu, M.; Bi, L. Influence of Interface Structure on Magnetic Proximity Effect in $\mathrm{Pt} / \mathrm{Y}_{3} \mathrm{Fe}_{5} \mathrm{O}_{12}$ Heterostructures. ACS Appl. Mater. Interfaces, 2016, 8, 8175-8183.

${ }^{13}$ Vélez, S.; Golovach, V. N.; Bedoya-Pinto, A.; Isasa, M.; Sagasta, E.; Abadia, M.; Rogero, C.; Hueso, L. E.; Bergeret, F. S; Casanova, F. Hanle Magnetoresistance in Thin Metal Films with Strong Spin-Orbit Coupling. Phys. Rev. Lett., 2016, 116, 016603.

${ }^{14}$ Flokstra, M. G.; Satchell, N.; Kim, J.; Burnell, G.; Curran, P. J.; Bending, S. J.; Cooper, J. F. K.; Kinane, C. J.; Langridge, S.; Isidori, A.; Pugach, N.; Eschrig, M.; Luetkens, H.; Suter, A.; Prokscha, T.; Lee, S. L. Remotely Induced Magnetism in a Normal Metal Using a Superconducting Spin-Valve. Nature Physics, 2016, 12, 57.

${ }^{15}$ Jensen, C.; van Slageren, J.; Jakes, P.; Eichel, R.-A.; Roduner, E. Support Effects on Hydrogen Desorption, Isotope Exchange, Chemical Reactivity and Magnetism of Platinum Nanoclusters in KL Zeolite J. Phys. Chem. C, 2013, 117, 22732-22745.

${ }^{16}$ Hembury, M.; Chiappini, C.; Bertazzo, S.; Kalber, T. L.; Drisko, G.L.; Ogunlade, O.; WalkerSamuel, S.; Krishna, K.,S.; Jumeaux, C.; Beard, P.; Kumar, C.S.; Porter, A. E.; Lythgoe, M. F.; Boissière, C.; Sanchez, C.; Stevens, M. M. Gold-Silica Quantum Rattles for Multimodal Imaging and Therapy. Proc Natl. Acad. Sci. USA, 2015, 17, 1959-1964.

${ }^{17}$ Karmakar, S.; Kumar, S.; Rinaldi, R.; Maruccio, G. Journal of Physics: Conference Series, 2011, 292, 012002. 
${ }^{18}$ Innocenzi, P.; Malfatti, L. L. Mesoporous Thin Films: Properties and Applications. Chem. Soc. Rev., 2013, 42, 4198-4216.

${ }^{19}$ Angelomé, P. C.; Liz-Marzán, L. M. , Synthesis and Applications of Mesoporous Nanocomposites Containing Metal Nanoparticles. J. Sol-Gel Sci. Technol., 2014, 70, 180-190.

${ }^{20}$ Wolosiuk, A.; Martínez, E. D.; Tognalli, V; Granada, M.; Fuertes, M. C.; Troiani, H.; Bilmes, S. A.; Fainstein, A.; Soler-Illia, G. J. A. A. Silver Nanoparticle-Mesoporous Oxide Nanocomposite Thin Films: a Platform for Spatially Homogeneous SERS-Active Substrates with Enhanced Stability. ACS Applied Mater. Interfaces, 2014, 6, 5263-5272.

${ }^{21}$ Fuertes, M. C.; Marchena, M.; Marchi, M. C. ; Wolosiuk, A.; Soler-Illia, G. J. A. A. Controlled Deposition of Silver Nanoparticles in Mesoporous Single- or Multilayer Thin Films: From Tuned Pore Filling to Selective Spatial Location of Nanometric Objects. Small, 2009, 5, $272-280$.

${ }^{22}$ Martínez, E. D.; Granja, L.; Bellino, M. G.; Soler-Illia, G. J. A. A. Electrical Conductivity in Patterned Silver-Mesoporous Titania Nanocomposite Thin Films: Towards Robust 3D NanoElectrodes. Phys. Chem. Chem. Phys. 2010, 12, 14445-14448.

${ }^{23}$ Crepaldi, E. L.; Soler-Illia, G. J. de A. A.; Grosso, D.; Cagnol, F.; Ribot, F.; Sanchez, C. Controlled Formation of Highly Organized Mesoporous Titania Thin Films: From Mesostructured Hybrids to Mesoporous Nanoanatase $\mathrm{TiO}_{2}$. J. Am. Chem. Soc., 2003, 125, 9770.

${ }^{24}$ Suda, M.; Kameyama, N.; Ikegami A.; Einaga, Y. Reversible Phototuning of the Large Anisotropic Magnetization at the Interface between a Self-Assembled Photochromic Monolayer and Gold. J. Am. Chem. Soc., 2009, 131, 865-870.

${ }^{25}$ Roncaroli, F.; Martínez, E. D.; Soler-illia, G. J. A. A.; Blesa, M. A. Mesoporous Thin Films of $\mathrm{TiO}_{2}$ on Attenuated Total Reflection Crystals. An In Situ Fourier-Transform Infrared Study of the Kinetics and Equilibrium of Adsorption and Photocatalysis of Carboxylic Acids J. Phys. Chem. C, 2013, 117, 15026-15034.

${ }^{26}$ Sánchez, V. M. ; Martínez, E. D.; Martínez Ricci, M. L.; Troiani, H.; Soler-Illia, G. J. A. A. Optical properties of Au nanoparticles included in mesoporous TiO2 thin films: a dual experimental and modeling study. J. Phys. Chem. C, 2013, 117, 7246.

${ }^{27}$ Boissiere, C.; Grosso, D.; Lepoutre, S.; Nicole, L.; Bruneau, A. B.; Sanchez, C. Porosity and Mechanical Properties of Mesoporous Thin Films Assessed by Environmental Ellipsometric Porosimetry. Langmuir, 2005, 21, 12362-12371.

${ }^{28}$ Thompkins, H. G.; McGahan, W. A. Spectroscopic Ellipsometry and Reflectometry, Wiley, 1999.

${ }^{29}$ Senftle, F. E.; Pankey, T.; Grant, F. A. Magnetic Suceptibility of tetragonal Titanium Dioxide. Phys. Rev.,1960, 120, 820.

${ }^{30}$ Chauvet, O.; Forro, L.; Kos, I.; Miljak, M. Magnetic Properties of the Anatase Phase of $\mathrm{TiO}_{2}$. Solid state Comm., 1995, 93, 667-669.

${ }^{31}$ Sarachik, M. P.; He, D. R.; Li, W.; Levy, M.; Brooks, J. S. Magnetic Properties of Boron- 
Doped Silicon. Phys. Rev. B: Condens. Matter Phys., 1985, 31, 1469.

${ }^{32}$ Sonder, E.; Stevens, D. K. Magnetic Properties of N-Type Silicon, Phys. Rev., 1958, 110, 1027.

${ }^{33}$ Sawicki, M.; Stefanowics, W.; Ney, Sensitive SQUID Magnetometry for Studying Manomagnetism A. Semicond. Sci. Technol., 2011, 26, 064006.

${ }^{34}$ Dutta, P.; Pal, S.; Seehra, M. S.; Anand, M.; B. Roberts, B. Magnetism in DodecanethiolCapped Gold Nanoparticles: Role of Size and Capping Agent. Appl. Phys. Lett., 2007, 90, 213102

${ }^{35}$ Wu, C.-M.; Li, C.-Y.; Kuo, Y.-T.; Wang, C.-W.; Wu, S.-Y.; Li, W.-H. Quantum Spins in Mackay Icosahedral Gold Nanoparticles. J. Nanopart. Res. 2010, 12, 177-185.

${ }^{36}$ Donnio, B.; GarcíaVázquez, P.; Gallani, J-L.; Guillon, D.; Terazzi, E. Dendronized Ferromagnetic Gold Nanoparticles Self-Organized in a Thermotropic Cubic Phase. Adv. Mat., 2007, 19, 3534-3439.

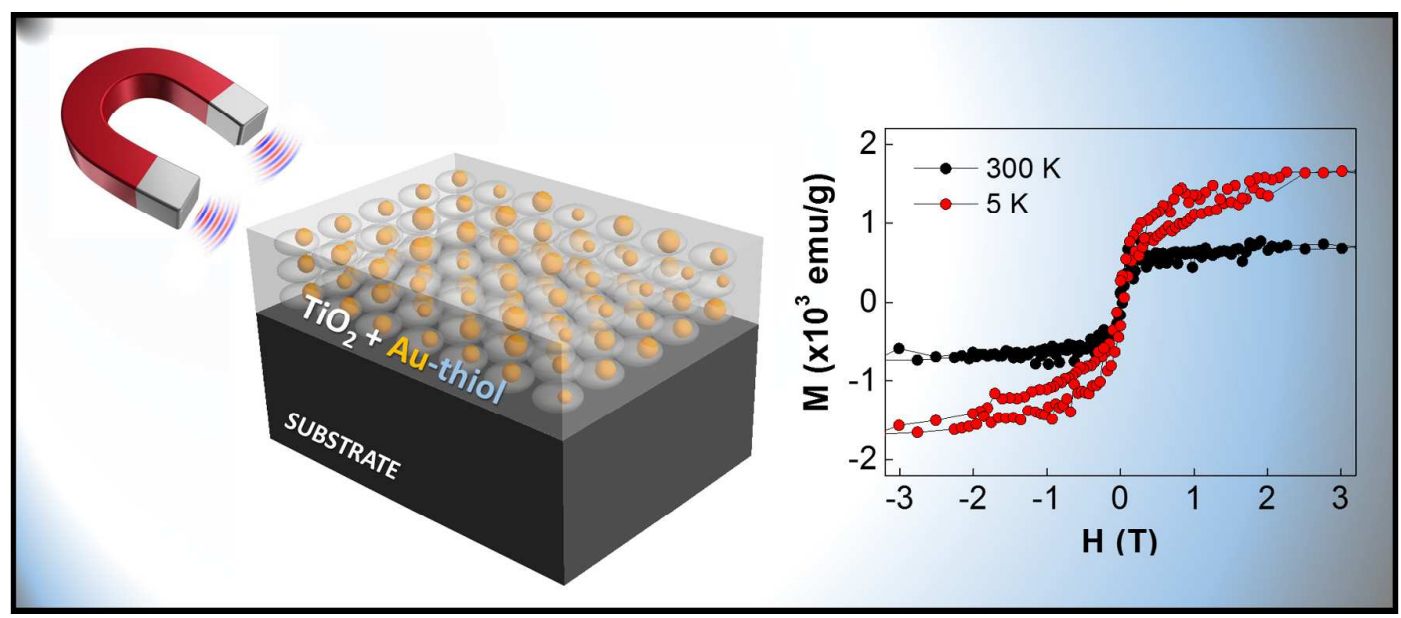

TOC FIGURE 